\title{
Social Life Cycle Assessment of a Concentrated Solar Power Plant in Spain: A Methodological Proposal
}

Corona, Blanca; Bozhilova-Kisheva, Kossara Petrova; Olsen, Stig Irving; San Miguel, Guillermo

Published in:

Journal of Industrial Ecology

Link to article, DOI:

10.1111/jiec. 12541

Publication date:

2017

Document Version

Peer reviewed version

Link back to DTU Orbit

Citation (APA):

Corona, B., Bozhilova-Kisheva, K. P., Olsen, S. I., \& San Miguel, G. (2017). Social Life Cycle Assessment of a Concentrated Solar Power Plant in Spain: A Methodological Proposal. Journal of Industrial Ecology, 21(6), 1566-1577. https://doi.org/10.1111/jiec.12541

\section{General rights}

Copyright and moral rights for the publications made accessible in the public portal are retained by the authors and/or other copyright owners and it is a condition of accessing publications that users recognise and abide by the legal requirements associated with these rights.

- Users may download and print one copy of any publication from the public portal for the purpose of private study or research.

- You may not further distribute the material or use it for any profit-making activity or commercial gain

- You may freely distribute the URL identifying the publication in the public portal 
Social Life Cycle Assessment of a Concentrated Solar Power plant in Spain: a methodological proposal

Corona, B. ${ }^{1}$, Bozhilova-Kisheva, K.P. ${ }^{2}$, Olsen, S.I. $^{2}$,San Miguel, G. ${ }^{1 *}$

${ }^{1}$ Universidad Politécnica de Madrid, c/José Gutiérrez Abascal 2, 28006 Madrid, Spain. Tel.: +34 914524862 .

${ }^{2}$ Technical University of Denmark, Department of Management Engineering, Division of Quantitative Sustainability Assessment, Nils Koppels Alle, Building 424, 2800 Kgs. Lyngby, Denmark.

*Corresponding author: g.sanmiguel@upm.es

\section{Abstract}

Measuring the sustainability of goods and services in a systematic and objective manner has become an issue of paramount importance. Life Cycle Sustainability Assessment (LCSA) is a holistic methodology whose aim is to integrate into a compatible format the analysis of the three pillars of sustainability, namely economy, environment and society. Social-Life Cycle Assessment (S-LCA) is a novel methodology still under development, employed to cover the social aspects of sustainability within LCSA. The aim of this article is to provide additional discussion on the practical application of S-LCA by suggesting a new classification and characterisation model which builds upon previous methodological developments. The structure of the social analysis has been adapted to maintain coherence with that of standard LCA. The application of this methodology is demonstrated using as a case study the analysis of power generation in a Concentrated Solar Power plant in Spain. The inventory phase was completed by using the indicators proposed by the UNEP/SETAC Guidelines on SLCA. The impact assessment phase was approached by developing a social performance indicator which builds on Performance Reference Points, an activity variable and a numeric scale with positive and negative values. The social performance indicator obtained $(+0.42$ over a range of $-2-+2)$ shows that the deployment of the solar power plant increases the social welfare of Spain, especially in the impact 
categories of Socio-economic sustainability and Fairness of relationships, whose results were 1.38 and 0.29 respectively.

Keywords

Social performance; social hotspots; social indicators; sustainability; LCSA;

\section{Introduction}

Sustainable development was defined in the Brundtland Report (Brundtland 1987) as the "development that meets the needs of the present without compromising the ability of future generations to meet their own needs". The same report stated that the notion of sustainability is based on three pillars, namely society, economy and environment. The United Nations Conference on Environment and Development (UNCED) in Río de Janeiro (1992) stated that sustainability was the main political goal for global future development (Kloepffer 2008). This trend has increased social and political pressure on companies and organizations worldwide to incorporate the principles of sustainable development into the development of their products and services.

In this context, measuring sustainability in a systematic and objective manner has become an issue of paramount importance. For this purpose, a holistic methodology named Life Cycle Sustainability Assessment (LCSA) is being developed in order to integrate the three pillars of sustainability under a life cycle approach. These procedures are based on the principles of ISO 14040 and 14044 and rely on the integration of Environmental Life Cycle Assessment (E-LCA), Lice Cycle Costing (LCC), and Social Life Cycle Assessment (S-LCA) methodologies (Cinelli et al. 2013).

Brent and Labuschagne (2005) sustains that the three pillars of sustainability should be assigned the same degree of importance. However, hitherto the life cycle assessment community has been paying considerably more attention to investigate environmental and economic issues, relegating the social pillar to a more marginal situation. Thus, while LCA and LCC are already considered as mature and widely established 
methodologies, S-LCA is still at its infancy in terms of methodological harmonization and recognition.

The purpose of S-LCA is to evaluate the social aspects associated with the life cycle of goods and services and also to identify the hotspots of the value chain where social risks may be higher. This should produce objective social criteria for technical and political decision-making and also the comparison of goods and services. The UNEPSETAC Life Cycle Initiative (UNEP-SETAC Life Cycle Initiative 2009) has been the main proponent and developer of S-LCA procedures. Despite being at a development stage, its "Guidelines for Social Life Cycle Assessment of Products" has become a landmark in the field.

The S-LCA methodology described in the UNEP-SETAC Guidelines (from now on "the Guidelines) draws largely on standard E-LCA methodology ISO 14040 and 14044 . Thus, the S-LCA framework consists also of four interconnected phases: goal and scope, inventory analysis, impact assessment and interpretation. Wherever possible, social impacts are also related to a functional unit that has been described for the good or service under consideration. Since social issues are mainly related to the activities/procedures of the companies involved in the provision of the goods and services considered, and also to other non-quantitative social aspects, processes may not be associated with a physical functional unit but with an activity variable that defines the weight of different companies or processes within the life cycle-(UNEPSETAC Life Cycle Initiative 2009). The unit most frequently used to quantify this activity variable is worker-hours.

Inventory data is an essential part of life cycle methodologies, determining the utility and accuracy of the final results. Unlike E-LCA and LCC, the S-LCA inventory data defines social relations and includes qualitative information, which increases the complexity of the inventory analysis phase.

Some authors suggest classifying social inventory data into two levels: (1) country level, which includes generic data on social issues referring to the country and the economic sectors where this activity takes place, and (2) the company/enterprise level, which includes inventory data specific to the organization involved (Macombe et al. 
2013; Martínez-Blanco et al. 2014; Dreyer, Hauschild, and Schierbeck 2006). This geographic scale approach allows to consider and compare social issues in every level of decision-making. Gathering of generic country level data may be assisted by official reports produced by well recognized organizations and also from international databases developed by the LCA community, such as the Social Hotspots Database (SHDB) (Benoit-Norris, Norris, and Aulisio 2013). Company site-specific company data is particular to each analysis (company, product, and location), increasing time/resources needs and also methodological complexity of the social analysis (Jørgensen et al. 2008).

Inventory data is usually transformed into a set of impact categories indicators in the impact assessment phase of the S-LCA. The practical application of this phase is considered to be the most controversial aspect (Petti, Ugaya, and Di Cesare 2014). There are two methodological approaches to this phase Parent et al. (2010): the Type 1 or Taskforce method, aimed at assessing social performance; and the Type 2 or Impact Pathway approach, aimed at assessing social impacts. The former uses Performance Reference Points (PRP) in the characterization step to quantify the significance of the data collected and an activity variable to weight the results according to the relative importance of each process within the life cycle of the product (UNEP-SETAC Life Cycle Initiative 2009). In the latter approach, the impact is assessed using impact pathways (Parent, Cucuzzella, and Revéret 2010). According to the S-LCA review published by Chhipi-Shrestha et al. (2015), 11 of the 20 studies revised used Type 1 impact assessment methods and the remaining 9 used Type 2. This review highlighted the lack of standardisation in the impact evaluation methods, the problem of ambiguity and weighting when referring to social impacts outside their specific culture and environment, the need to incorporate not only negative but also positive impacts, the importance of using site-specific inventory data and the utility of using SHDB as a tool for data research prioritization.

The Guidelines define a set of stakeholder categories to classify the social performance of the system under investigation into a series of subcategories. However, 
subcategories are not clearly classified into impact categories ${ }^{1}$. The Guidelines specify that impact categories should represent social issues of concern, covering human rights, working conditions, health and safety, cultural heritage, governance, and socioeconomic repercussions. Aside from these general social issues, no characterization models have been commonly accepted by S-LCA practitioners (Chhipi-Shrestha, Hewage, and Sadiq 2015).

Most authors agree that, despite the need for further work, S-LCA methodology is at a sufficiently advanced stage to allow the production of preliminary and simple analyses that may contribute to address the social area of LCSA. However, the methodology requires extensive refining and testing in order to allow a precise analysis of more complex systems (Macombe et al. 2013; Ekener-Petersen and Finnveden 2013). In this respect, this article aims to presents a case study of S-LCA applied to electricity generation in a Concentrated Solar Power (CSP) plant, contributing to the development of methodology with a new classification and characterization method based on a social performance indicator. The novelty of this study primarily relates to the development and application of a positive-negative numerical scale for the sitespecific assessment of the CSP technology combined with the development and application of the seven rules method for the meaning assessment step. These elements were integrated to provide a full example of a complete S-LCA assessment incorporating both a generic and a specific analysis approach. It should also be noted that there are very little examples of S-LCA so far. Therefore, although most of the methodology applied follows the guidelines proposed by UNEP-SETAC and SHDB, the value of the article resides in the choices and the integration of the different methodology options proposed by S-LCA community in a coherent and easy-tounderstand way. This article also aims to bring about discussion regarding methodological differences between conventional LCA and S-LCA, which should be taken into account when evaluating the social area of a LCSA.

\footnotetext{
${ }^{1}$ As stated by the Guidelines, impact categories are defined as logical groupings of S-LCA results, related to social issues of interest to stakeholders and decision makers.
} 
In addition, the results of this study provide information about the social implications associated with the use of concentrating solar power in Spain. Although the environmental and economic impacts of this technology have been estimated by different authors (Corona and San Miguel 2015; San Miguel and Corona 2014; Burkhardt, Heath, and Turchi 2010; Klein and Rubin 2013; Caldés et al. 2009), social issues associated with the life cycle of this technology were not previously addressed.

\section{Methodology: application to a case study}

\section{Characteristics of the case study}

The system under study is a commercial 50-MWe CSP plant based on parabolic trough technology and located in Ciudad Real, Spain. The installation uses synthetic oil as HTF and incorporates a 7.5-h molten salt TES based on two-tank configuration. The facility occupies 200 ha of non-productive rural land and its lifetime expectancy is 25 years. The CSP plant consumes natural gas as auxiliary fuel to increase electricity generation. This additional energy allows producing $15 \%$ of the electricity generated by the power plant. The plant allows 3,290 h/year of full load operation for a gross electricity output of 194,926 MWh/year. Net electricity sales after deducting onsite requirements and grid inefficiencies represent $163,738 \mathrm{MWh}$ /year.

\section{Scope and objectives}

This study has three main objectives:

- To explore the use of S-LCA methodology following principles presented in the UNEP/SETAC Guidelines and the SHDB database and contribute with a case study to the pool of existing knowledge.

- To propose and test a new impact assessment method (Type 1) and a social performance indicator to measure the social performance of an energy system within a region.

- To investigate the social performance of the CSP technology in Spain in order to identify social hotspots and find points where negative social impacts may be reduced. 
The function of a CSP plant is to produce electricity and the functional unit considered in this analysis is $1 \mathrm{MWh}$. The life cycle of the energy system considers four life phases: Extraction of raw materials and Manufacturing of components (E\&M), Construction of the facility (C), Operation and Maintenance of the power plant (O\&M) and Dismantling and Disposal of waste (D\&D).

This study follows the cradle to gate approach, not including transportation and consumption of electricity. This decision was based on the fact that every electricity generation technology shares the same transport and consumption phase, and the consumer has no real power to choose which technology is producing the electricity purchased. This S-LCA analysis considers four stakeholders: Workers, Local community, Society and Value chain actors. The Consumer stakeholder (and its subcategories) was not considered since the consumption of electricity (and its social repercussions) was left out of the scope of this study.

The first step in this S-LCA analysis was to perform a social hotspots analysis in order to detect potential social risks in the life cycle of the system. A social hotspot refers to a specific situation within a region that can be regarded as a problem, a risk or an opportunity in terms of social concern (UNEP-SETAC Life Cycle Initiative 2009). After the hotspots analysis, a site-specific assessment was conducted at the company level in order to assess the significance of the specific issues and potential risks detected.

The impact assessment phase in this study follows a Type 1 approach, a decision which has been based on the complexity and lack of information regarding cause-effect relationships for the energy system (UNEP-SETAC Life Cycle Initiative 2009; ChhipiShrestha, Hewage, and Sadiq 2015). Parent et al. (2010) encourage to use the term "social performance" instead of "social impact" when using the Type 1 assessment approach, since the use of Performance Reference Points "gives an indication about the state of a dimension of the social contexts found along the life cycle" rather than "the social consequences of" the system. Therefore, although the term "Impact categories" will be used, the results actually refer to the positive or negative social performance on social issues concerning human well-being. 
A critical review of the social assessment was performed by members of a national NGO whose field of action is related to the electricity sector (Engineering Without Borders).

\section{Inventory data collection}

This section describes the inventory data collected and employed in both stages of the S-LCA: the social hotspots analysis and the site-specific assessment.

\section{Social hotspots analysis}

The social hotspots analysis was performed by exploring social issues taking place in every country providing goods or services to the system under study. The Social Hotspots Database (SHDB) (Benoit-Norris, Norris, and Aulisio 2013) implemented in Simapro was used to model the global supply chain of all the products and services. This simulation was based on the monetary costs of each of the components and processes considered in the life cycle of the power plant. The cost of each of these items was converted from $€ 2013$ to $€ 2002$ (SHDB unit) using OECD CPI index and Market exchange rates (OECD 2014) and assigned as a demand to the corresponding economic sector of the producer country. The SHDB links the demand of goods and services from each sector/country with their corresponding social risks and opportunities considering over 100 different social indicators. The impact evaluation method of the SHDB aggregates the social risks associated with the demand of goods and services throughout the life cycle of the system. Finally, the results of the social hotspots analysis represent the social risks associated with each component and process of the system's life cycle in different social issues and categories.

The economic inventory necessary for the hotspots analysis of the CSP power plant was provided by the engineering firm IDie.

Site-specific assessment

The main approach to produce a site-specific S-LCA involves exploring how the related organizations perform on social and socio-economic aspects throughout the life cycle of the system under study. To this purpose, the following inventory data was collected: activities carried out by the companies involved in the life cycle of the CSP plant and 
number of worker hours per life stage as the activity variable. The number of worker hours per life phase and process was obtained as a result of a socio-economic Input Output Analysis of the system under study (published in (Corona, de la Rúa, and San Miguel 2016).

The promoter company is in charge of the project development, construction, operation and dismantling of the power plant. Additional suppliers provide different power plant components. The site-specific data collection was related to the promoter company. The companies carrying out activities taking place in the E\&M and Disposal phases were left out of the scope of the site-specific study. However, some recommendations were made on the basis of the hotspots analysis results.

The promoter company belongs to a business group which operates in the Construction and Industrial Services sectors. Site-specific inventory data for the promoter company and the business group was obtained by web research, from direct communication with the company and by revising the following corporate reports:

- The annual Corporate Social Responsibility (CSR) Report of the business group, which has been produced according to the Global Reporting Initiative (GRI) standards (year 2014).

- The annual Corporate Report of the promoter company (year 2013).

- The collective bargaining agreement (CBA) produced by a subsidiary of the promoter company (year 2010).

In order to understand the meaning and magnitude of the inventory data gathered in this step -i.e. to estimate the positive or negative impacts caused by the promoter company in the social environment- it is necessary to collect data which will serve as Performance Reference Points. In the case of study, the average performance in Spain was taken as reference. Since most of the system's life cycle takes place in Spain, the Spanish average allows to estimate if the social performance of the company within the life cycle of the system is representing a positive or negative impact with respect to the specific social environment (Spain). The Performance Reference Points data (average wage in the economic sector, average female jobs...) was collected from official generic sources such as national statistics (National Statistics Institute in Spain, 
Spanish Official State Bulletin), international organizations (International Labour Organization, Organization for Economic Co-operation and Development, Eurostat), and also from the national media. The specific source for each Performance Reference Point is described in the supplementary information.

In order to maintain temporal validity, inventory data used in this analysis was produced less than 5 years prior to the initiation of the energy project (in 2013). The inventory indicators for each subcategory and life stage are described in tables S5 and S6 of the Supplementary Information. Twenty four different indicators have been considered in this site-specific analysis, 11 of which are quantitative, 10 are semiquantitative and 3 are qualitative.

\section{Impact assessment}

Data was classified, aggregated and evaluated using different methods depending on the assessment step: hotspots analysis and site-specific assessment. The new method employed in this analysis was built according to the preferences stated in the Guidelines and reported by the scientific community. The aim was to offer a simplified impact assessment method, easy to understand by stakeholders and able to present results in a transparent and simple way. A new classification of subcategories into impact categories is also proposed. This section describes firstly the hotspots analysis approach, and later the methodological proposal for the classification and characterization of social impacts in the site-specific assessment.

\section{Hotspots analysis}

The impact evaluation method Social LCIA Method 1 developed by New Earth and adapted to SimaPro software was applied for the hotspots analysis. This method gathers data for 22 social themes which fall under 5 social categories as follows: Labour rights and decent work, Health and safety, Human rights, Governance and Community infrastructure. Each social issue is characterized into social themes by considering the level of risk identified for each social issue. Then, social themes are aggregated into social categories by applying weighting factors. Results obtained by this method represent the risk of different social problems taking place in different 
countries and economic sectors. These risks will serve as a basis for prioritizing sitespecific research.

\section{Site-specific assessment}

The characterization and normalization step in S-LCA cannot be approached the same way as in Environmental LCA, since inventory data is not quantitative and the conversion of social data into a single impact category unit is not straightforward, objective or subject to environmental sciences. For this reason, the characterisation, normalisation and weighting of subcategories in the site-specific assessment are performed as a single step, also referred to as the meaning assessment step in the Guidelines.

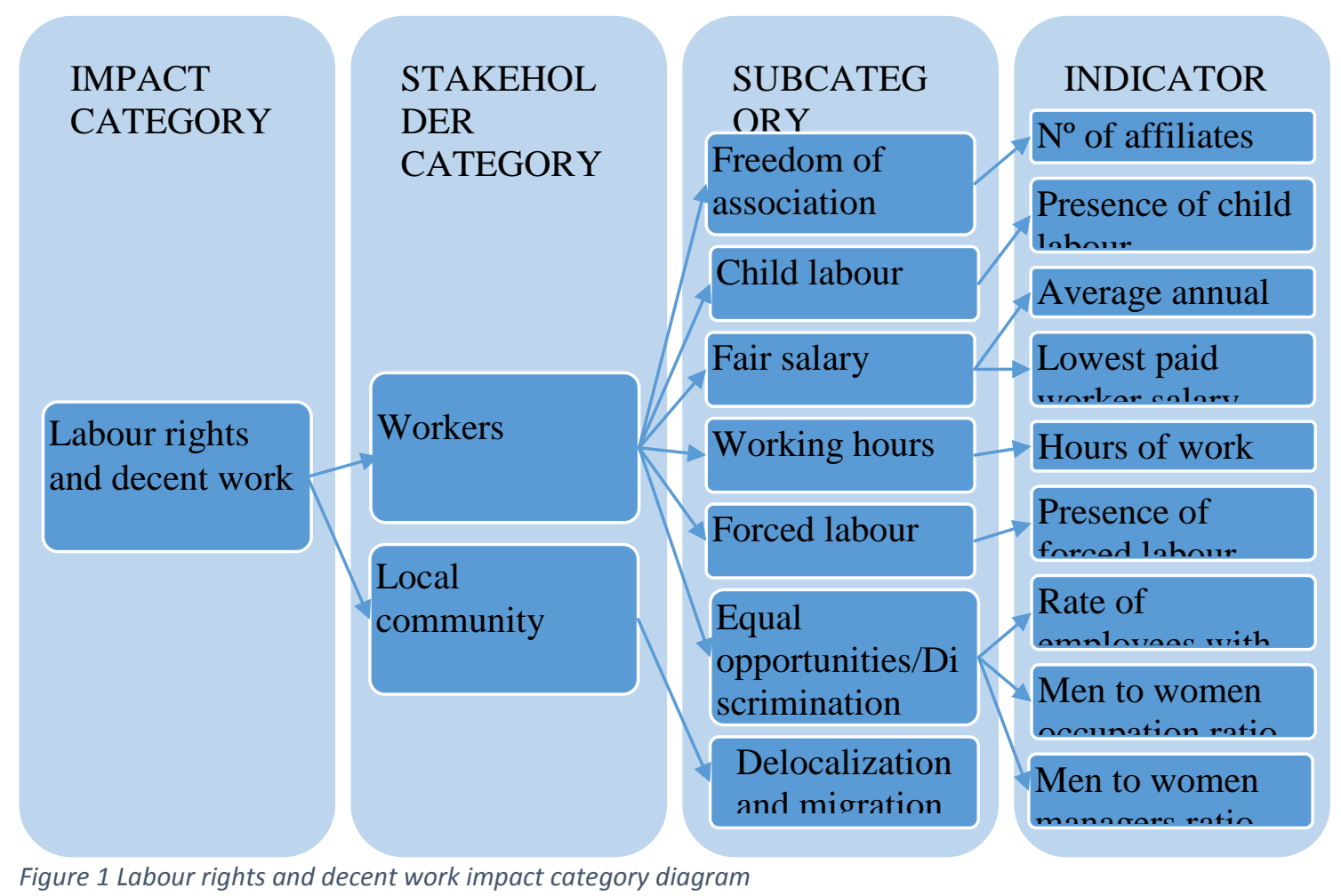

\section{Classification and Meaning assessment step}

As an example, Figure 1 shows a diagram representing the subcategories and indicators associated with one impact category (Labour rights and decent work). The Guidelines propose 31 subcategories, classified into 5 stakeholder categories. Although this classification is widely described in the Methodological Sheets (Benoît Norris et al. 2013), the classification and characterisation step of subcategories into impact 
categories is not officially developed yet. Therefore, a classification procedure was created for the purpose of this study. The meaning assessment step applied has some similarities with the one developed by Ciroth and Franze (2011), however, it presents the following differences: positive and negative impacts are represented in the results, all the guideline's subcategories are included even if they are not significantly affected, and a life phase aggregation using work hours as activity variable is included.

The following impact categories have been considered: "Labour rights and decent work", "Health and safety", "Cultural and natural heritage", "Fair relations" and "Socioeconomic sustainability". The subcategories classification into impact categories proposed in this study is described in Table 3 in the Results sections. Besides, a new subcategory has been added to the "socio-economic sustainability" impact category: product social utility. The selection and classification of these subcategories is argued and justified in the Supplementary Information.

The meaning assessment step was made according to the following seven rules (see Figure 2 for a visual diagram):

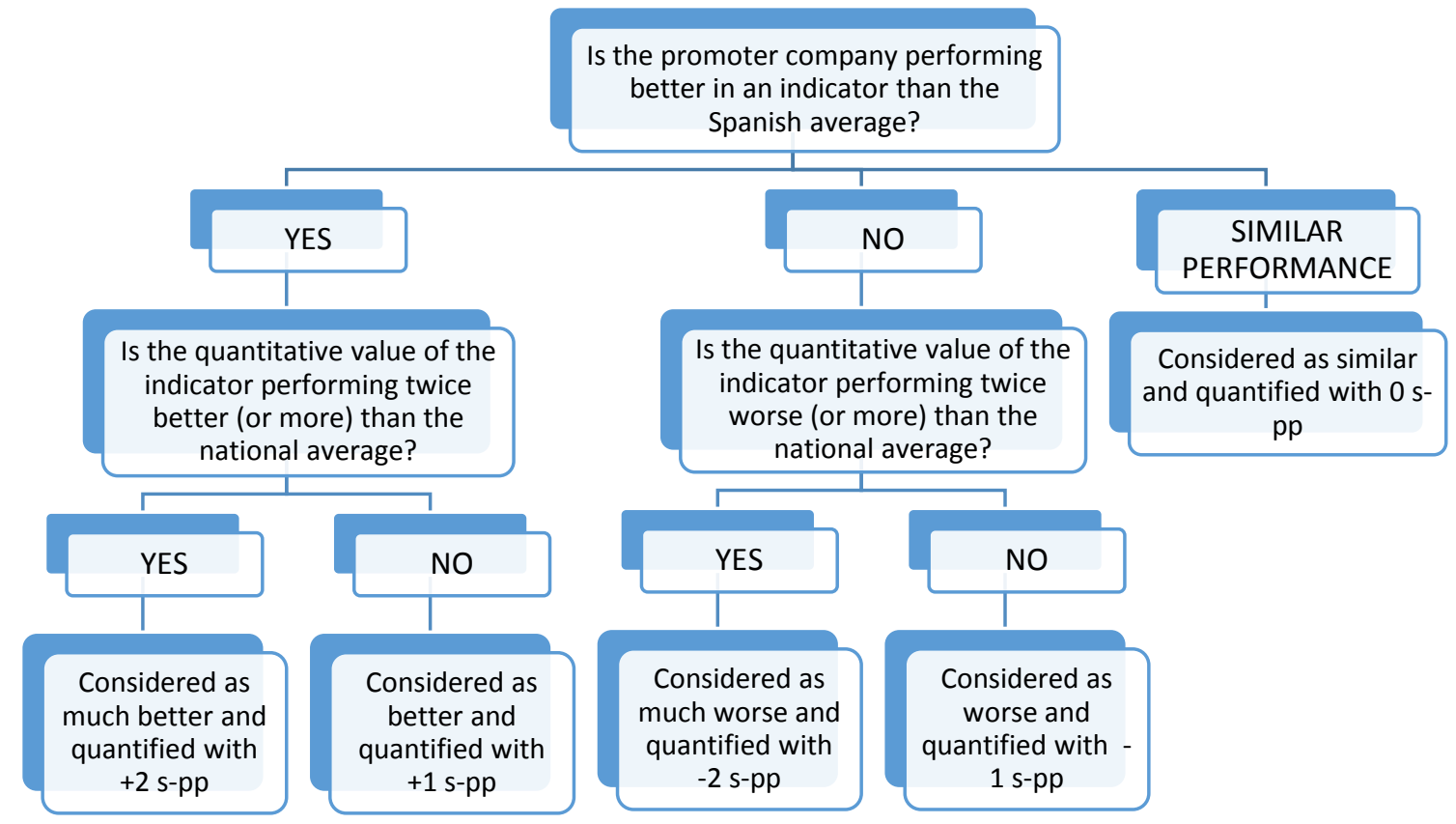


1. When the promoter company performed better in an indicator than the Spanish average, the social performance in that indicator was considered as "better" and quantified with +1 social-performance points (s-pp).

2. If the quantitative value of the indicator was performing twice better (or more) than the national average, then it was considered as "much better" and quantified with $+2 \mathrm{~s}-\mathrm{pp}$.

3. When the indicator showed similar results than the national average, then it was considered as "similar" and quantified with 0 s-pp.

4. When it showed a worse social performance, it was considered as "worse" and quantified with -1 s-pp (one negative point).

5. When the indicator was performing twice worse (or more) then it was rated as "much worse" and quantified with -2 s-pp (two negative points).

6. When there was not any information about the subcategory indicators, but there was low social risk in the subcategory (determined by the social hotspots analysis), it was considered as "similar" and quantified with 0 s-pp.

7. When one subcategory had several indicators, an average of the assigned s-pp is assumed as the subcategory score. When a category has different subcategories, an average of the assigned subcategory score is used as the category score.

The fact that the promoter company operates in different life cycle phases (C, O\&M and D), corresponding to different economic sectors, means that, despite being the same company, it may perform differently in each phase. These differences are derived from the average (country) and specific (company) social performance on the corresponding economy sector (C and D: construction sector; O\&M: Energy supply sector). In order to consider the relative importance of the results in each phase, the activity variable "work hours" is used as weight, taking into account the amount of work hours invested in each phase of the power plant's life cycle (considering only $C$, O\&M and $D$ phases).

Finally, the total scores for each impact category are aggregated in the weighting step, resulting in a final score. Since there is not any guidance at present for weighting in SLCA, the same importance has been given to every impact category, although it is 
acknowledged that some subcategories might represent higher social interest than others.

This simplified quantification method allows estimating whether the social performance of the company has a positive, negative or unaffected social impact as a whole within the country. A positive weighted value as final score would represent a benefit in the social performance of the country, a negative weighted value would represent damage in the national social performance, and a weighted value close to zero would represent that the social environment would be neither positively nor negatively affected. This simplification must be taken carefully, and always presented with the subcategories indicators, since a close-to-zero score does not mean that the social performance of the company is not generating damages or benefits within the social issues of interest, but that the average weighted social performance of the country remains neutral.

The meaning assessment step is described in Table 3, while the characterization of each indicator is described in the supplementary information.

\section{RESULTS AND DISCUSSION}

\section{Generic social risk assessment: Hotspots analysis}

Figure 3 shows the characterised results from the social hotspots analysis applied to the CSP plant in Spain per subcategory and life cycle phase. The O\&M phase accumulates the highest risks, especially in Forced Labour (90\% of the life cycle impact in this subcategory), Indigenous Rights (90\%), Poverty wage (89 \& $86 \%$ ) and Gender equity (89 \%). E\&M phase is the next phase with highest risks, especially in Toxics \& Hazards (25\%) and Improved Sanitation (20\%). The high social risk obtained in O\&M phase is derived from the consumption of imported natural gas, since this activity represents between 70 and $97 \%$ of the social risk for almost every category within this phase. 


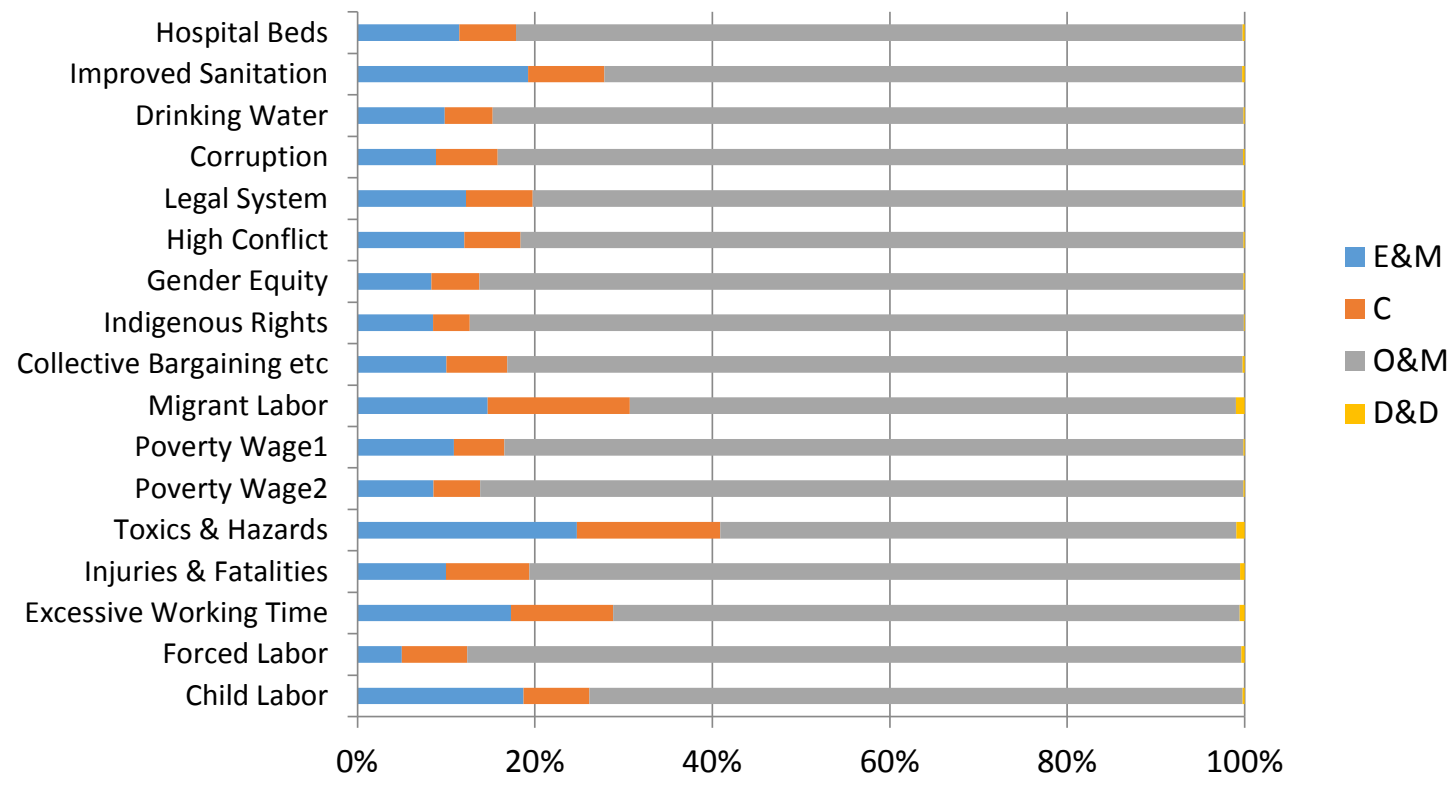

Figure 3 Characterisation results for the Social Hotspots Analysis of a CSP plant per subcategory and life phase

The weighted results (shown in Figure 4) represent the risks in social issues after the allocation of weights to each subcategory and social category. These results suggest that Health \& Safety is the social category with higher risks for every life phase, followed by Labor Rights \& Decent Work. The process presenting highest risk for Health \& Safety and Labor Rights \& Decent Work categories in the life cycle is mainly NG provision (a contribution of $52 \%$ and $71 \%$ respectively), but also payment of bank interests ( $18 \%$ and $8 \%$ respectively).

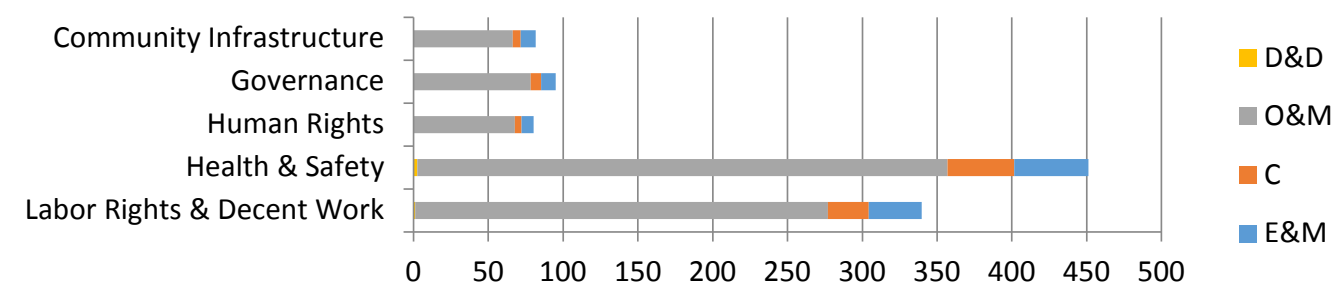

Figure 4 Weighting results for the Social Hotspots Analysis of a CSP plant per category and life phase

The economic sectors with weighted social risks higher than $1 \%$ of total life cycle risks of the CSP plant are described in Table 1. This table also includes the corresponding share of social risk for each economic sector in each life phase. The high share of social risk in different sectors can be explained by two reasons: the amount of money spent in that sector and the level of risk for social issues occurring in such sector. 
Table 1 Economic sectors contribution of each life phase of the CSP plant to more than $1 \%$ of the weighted social risks.

\begin{tabular}{|c|c|c|c|c|c|}
\hline & $\begin{array}{l}\text { E\&M } \\
(\%)\end{array}$ & C (\%) & $\begin{array}{l}\text { O\&M } \\
(\%)\end{array}$ & $\begin{array}{l}\text { D\&D } \\
(\%)\end{array}$ & \begin{tabular}{|l} 
Total \\
$(\%)$
\end{tabular} \\
\hline Commerce/DZ & 1.2 & 8.3 & 35 & 0.9 & 29 \\
\hline Financial services nec/ES & 0.8 & 1.4 & 10 & 1.2 & 8.2 \\
\hline Gas/PE & 0.00 & 0.00 & 8.0 & 0.0 & 6.4 \\
\hline Construction/ES & 2.2 & 30 & 0.6 & 58 & 3.6 \\
\hline Communication/DZ & 0.1 & 1 & 4.09 & 0 & 3.4 \\
\hline Vegetables, fruit, nuts/DZ & 0.13 & 0.95 & 4.0 & 0.10 & 3.3 \\
\hline Transport nec/DZ & 0.1 & 1 & 3.7 & 0.1 & 3.0 \\
\hline Gas/DZ & 0.05 & 0.53 & 2.8 & 0.05 & 2.3 \\
\hline Business services nec/ES & 1.9 & 2.8 & 1.8 & 2.6 & 1.9 \\
\hline Gas/EG & 0.03 & 0.03 & 2.1 & 0.02 & 1.7 \\
\hline Animal products nec/DZ & 0.07 & 0.46 & 2.0 & 0.05 & 1.6 \\
\hline Electricity/ES & 0.2 & 5.8 & 1.1 & 0.1 & 1.4 \\
\hline Metal products/ES & 9.8 & 2.3 & 0.1 & 1.9 & 1.4 \\
\hline Commerce/ES & 5.3 & 2.7 & 0.6 & 2.9 & 1.3 \\
\hline Other sectors & 74 & 40 & 23 & 32 & 30 \\
\hline
\end{tabular}

${ }^{*} \mathrm{DZ}=$ Algeria, $\mathrm{ES}=$ Spain, $\mathrm{PE}=$ Peru, $\mathrm{EG}=$ Egypt

As observed in this table, there are four countries presenting economic sectors with high social risk: Algeria, Spain, Peru and Egypt. Except for Spain, the risk from these countries is associated with the consumption of natural gas ( $37 \%$ of the natural gas is assumed to be imported from Algeria, $5.6 \%$ from Peru, and $1.5 \%$ from Egypt). 
The Spanish economic sectors contributing the most to the social risks associated with the CSP plant are Financial services nec/ES (in O\&M phase), Construction/ES (in C and D\&D phases) and Business services nec/ES. The high share of social risk in Financial services nec/ES (11\%) is mainly due to the sum of money spent in this sector, which amounts to $128 \mathrm{M} \$_{2002}$. According to the SHDB, this sector presents "very high risks" in the following social issues: corruption over the last 3 years, non-fatal and fatal injuries, risk that the migrant workers are treated unfairly, and risk of HIV. The demand of goods and services to the Construction/ES sector amounts to $58 \mathrm{MS}$, and is mainly related to the construction and demolition of the power plant ( $C$ and $D \& D$ phases). This sector presents high and very high social impacts in the same issues as the Financial services nec./ES, but including unemployment as "very high risk", and gender inequality in the workforce and forced labour as "high risk".

In order to determine the social hotspots taking place in the manufacturing of the power plant components, Table 2 shows the economic sectors causing more than $2 \%$ of the social risks within the E\&M phase. This table presents the contributions of each subsystem of component of the CSP plant (including manufacturing and transport to de power plant) to the weighted social risks in each economic sector. The subsystem presenting the highest weighted risks is the solar field (34\% of the social risks in E\&M phase), followed by Thermal storage (31\%), Power block (17\%), HTF system (14\%) and Facilities (3.4\%).

Table 2 Economic sectors contribution to more than $2 \%$ of the weighted social risks in the components manufacture and transport (E\&M) of the CSP plant

\begin{tabular}{|c|c|c|c|c|c|}
\hline & $\begin{array}{l}\text { HTF } \\
\text { System } \\
(\%)\end{array}$ & $\begin{array}{l}\text { Solar } \\
\text { field } \\
\text { (\%) }\end{array}$ & $\begin{array}{l}\text { Therma } \\
\text { I } \\
\text { Storage } \\
\text { (\%) }\end{array}$ & $\begin{array}{l}\text { Power } \\
\text { block } \\
\text { (\%) }\end{array}$ & $\begin{array}{l}\text { Facilitie } \\
\text { s } \\
\text { (\%) }\end{array}$ \\
\hline Metal products/ES & 14 & 22 & 0.2 & 1.5 & 2.0 \\
\hline Business services nec/CL & 0.02 & 0.1 & 21 & 0.0 & 0.0 \\
\hline Commerce/ES & 9.7 & 4.6 & 1.8 & 9.7 & 4.3 \\
\hline
\end{tabular}




\begin{tabular}{l|lllll|}
\hline Commerce/AO & 1.4 & 0.9 & 11 & 1.0 & 0.7 \\
\hline $\begin{array}{l}\text { Machinery and equipment } \\
\text { nec/ES }\end{array}$ & 6.7 & 1.0 & 1.6 & 12 & 4.7 \\
\hline Minerals nec/CL & 0.01 & 0.02 & 11 & 0.01 & 0.01 \\
\hline Metals nec/MZ & 4.0 & 5.1 & 0.5 & 3.3 & 1.3 \\
\hline Commerce/MZ & 3.3 & 4.2 & 0.4 & 2.7 & 1.1 \\
\hline Electricity/MZ & 3.2 & 4.0 & 0.4 & 2.6 & 1.0 \\
\hline Construction/ES & 0.9 & 0.6 & 0.2 & 0.9 & 50 \\
\hline Other sectors (\%) & & & & & \\
\hline
\end{tabular}

*ES=Spain, $\mathrm{CL}=$ Chile, $\mathrm{AO}=$ Angola, $\mathrm{MZ}=$ Mozambique

As observed in Table 2, there are four countries presenting economic sectors with high share of weighted social risks: Spain, Chile, Angola and Mozambique. The contribution of Spain and Chile is directly related to the manufacturing of plant components. However, Angola and Mozambique were not expected to present a high share of risks. Although the demand for goods and services from Angola is relatively low (7,090 \$2002 in the Commerce/AO sector), the social risks are very high in multiple social issues. The connection of Angola's commerce with the power plant is derived from the demand of Chilean molten salts in the Chilean Minerals nec sector, since Chile imports minerals from Angola. However, it is known that molten salts are extracted from Chilean soil, not imported from any country. Therefore, in this specific case, Commerce in Angola is not affected by the consumption of molten salts in the CSP plant.

Mozambique presents high risks via its Metals nec, Commerce, and Electricity sectors. These risks are all derived from the demand of 43,000 \$2002 from the Mozambican Metals nec sector. The connection of this sector with the power plant is associated with the import of Mozambican metals from the following Spanish sectors: Metals nec, Electronic equipment and Machinery and equipment. However, the main exported metal from Mozambique to Spain is aluminium (Ministry of foreign affairs 2015), which in the case under study is not used in significant quantities. Therefore, the risks 
presented by the SHDB in this country are probably overestimated, due to metals aggregation in the Metals nec/ES sector.

The economic sector of Metal products/ES is also presenting a high share of social risks due to the demand for metals. According to the SHDB, this sector has the same high and very high risks as the Financial services nec sector, but including unemployment as very high risk, and gender inequality in the workforce as high risk.

According to these results, the suppliers that should be site-investigated in Spain are the ones providing metal products, machinery and equipment. The specific issues presenting hotspots in Spain are related to gender inequality, corruption, injuries and immigrants. Regarding hotspots taking place in other countries, social issues associated with the Chilean suppliers of molten salts should be investigated, since it is the second sector with highest weighted risks taking place in the E\&M phase.

\section{Site-specific assessment}

This section presents the results of the site-specific assessment, which represents the social performance of the promoter company in the foreground processes of the CSP plant. Table 3 describes the meaning assessment results for each subcategory and impact category.

Table 3 Meaning assessment step: Results for Impact categories and Subcategories considered in the site specific social impact assessment

\begin{tabular}{|c|c|c|c|c|c|c|}
\hline \multirow[t]{2}{*}{ Categories } & \multirow[t]{2}{*}{ Subcategories } & \multirow{2}{*}{$\begin{array}{l}\text { Corresponding } \\
\text { Stakeholder } \\
\text { category }\end{array}$} & \multicolumn{2}{|c|}{$\begin{array}{l}\mathrm{C} \text { and } \mathrm{D} \\
\text { phases }\end{array}$} & \multicolumn{2}{|c|}{$\begin{array}{l}\text { O\&M } \\
\text { phase }\end{array}$} \\
\hline & & & $\mathrm{Ch}^{*}$ & $\mathrm{~W}^{*}$ & $\mathrm{Ch}^{*}$ & $\mathrm{~W}^{*}$ \\
\hline \multirow{7}{*}{$\begin{array}{l}\text { Labour rights } \\
\text { and decent } \\
\text { work }\end{array}$} & $\begin{array}{l}\text { Freedom of association and } \\
\text { collective bargaining }\end{array}$ & Workers & 1 & \multirow{7}{*}{0.21} & 0.50 & \multirow{7}{*}{0.16} \\
\hline & Child labour & Workers & 0 & & 0 & \\
\hline & Fair salary & Workers & -0.33 & & -1 & \\
\hline & Working hours & Workers & 1 & & 1 & \\
\hline & Forced labour & Workers & 0 & & 0 & \\
\hline & $\begin{array}{l}\text { Equal } \\
\text { opportunities/Discrimination }\end{array}$ & Workers & -0.67 & & $\begin{array}{l}- \\
0.67\end{array}$ & \\
\hline & Delocalization and migration & Local community & 0 & & 0 & \\
\hline
\end{tabular}




\begin{tabular}{|c|c|c|c|c|c|c|}
\hline \multirow{4}{*}{$\begin{array}{l}\text { Health } \\
\text { safety }\end{array}$} & Health and safety & Workers & 1 & \multirow{4}{*}{0.25} & 1 & \multirow{4}{*}{0.25} \\
\hline & Social Benefit/Social security & Workers & 0 & & 0 & \\
\hline & $\begin{array}{l}\text { Safe and healthy living } \\
\text { conditions }\end{array}$ & Local community & 0 & & 0 & \\
\hline & Secure living conditions & Local community & 0 & & 0 & \\
\hline \multirow{5}{*}{$\begin{array}{l}\text { Cultural } \\
\text { natural } \\
\text { heritage }\end{array}$} & Access to material resources & Local community & 0 & \multirow{5}{*}{0} & 0 & \multirow{5}{*}{0} \\
\hline & Cultural heritage & Local community & 0 & & 0 & \\
\hline & Respect of indigenous rights & Local community & 0 & & 0 & \\
\hline & $\begin{array}{l}\text { Prevention and mitigation of } \\
\text { armed conflicts }\end{array}$ & Society & 0 & & 0 & \\
\hline & Access to immaterial resources & Local community & 0 & & 0 & \\
\hline \multirow{7}{*}{$\begin{array}{l}\text { Fairness of } \\
\text { relationships }\end{array}$} & Corruption & Society & -1 & \multirow{7}{*}{0.29} & -1 & \multirow{7}{*}{0.29} \\
\hline & Fair Competition & Value chain actors & -1 & & -1 & \\
\hline & Supplier Relationships & Value chain actors & 1 & & 1 & \\
\hline & $\begin{array}{l}\text { Respect to intellectual property } \\
\text { rights }\end{array}$ & Value chain actors & 0 & & 0 & \\
\hline & Promoting Social Responsibility & Value chain actors & 1 & & 1 & \\
\hline & $\begin{array}{l}\text { Public commitments to } \\
\text { sustainability issues }\end{array}$ & Society & 2 & & 2 & \\
\hline & Community engagement & Local community & 0 & & 0 & \\
\hline \multirow{4}{*}{$\begin{array}{l}\text { Socio- } \\
\text { economic } \\
\text { Sustainability }\end{array}$} & Local employment & Local community & 1 & \multirow{4}{*}{1.38} & 1 & \multirow{4}{*}{1.38} \\
\hline & \begin{tabular}{|lll} 
Contribution to economic \\
development
\end{tabular} & Society & 2 & & 2 & \\
\hline & Technology Development & Society & 0.5 & & 0.5 & \\
\hline & Product social utility & Society & 2 & & 2 & \\
\hline
\end{tabular}

\section{${ }^{*} \mathrm{Ch}=$ Characterization. $\mathrm{W}=$ Weighting}

Most of the indicators and subcategories were characterised as presenting positive social performance comparing to the Spanish average. The only subcategories presenting a worse than similar performance are Fair salary, Discrimination, Fair competition, and Corruption.

The only indicator performing worse in Fair salary is wage inequality, since the salary of the executive managers in the promoter company is $771 \%$ higher than the average salary in the company, while the average salary for executive managers in the Spanish 
construction sector is only $134 \%$ higher (INE 2014, 1-10). Regarding the Discrimination subcategory, the "Men to women occupation ratio in the company" indicator is performing worse in the promoter company with a 7.92 ratio of men to women (Annual Corporative Report) compared to the Spanish 6.34 average ratio for 2013 in the corresponding sectors (INE 2015). In addition, the "Men to women executive managers' ratio in the company" indicator is performing much worse, with a 22 ratio of men to women executive managers (Annual Corporative Report) compared to the 2.75 Spanish average ratio considering every sector (INE 2015). Since gender inequality was highlighted as a social hotspot in the hotspots analysis, and also presented negative indicators in the site-specific assessment, this issue was further investigated by further reviewing the company reports. The CSR Report of the business group of the promoter company has an unexplained absence of reported indicators related to gender issues.

The Fair competition category was measured by the indicator: "Legal actions during the reporting period (as company being membership in alliances behaving in an anticompetitive way)". The web research revealed two legal actions rejected by the National Committee of the Markets and Competition involving the promoter company and one legal action executed against the business group of the promoter company. Since two out of three legal actions were rejected by the National Committee, the indicator was ranked as worse (and not as much worse).

The subcategory corruption is semi-quantitative and consists of only one indicator: "There have been legal actions related to corruption during the reporting period". The internet research revealed several legal actions against the promoter company and its affiliates, between year 2010 and 2014. The company has been accused of accounting fraud and embezzlement of public funds. However, these legal actions have not been resolved yet. Although this situation may be regarded as similar to the national average, where the social risk in corruption is very high according to the SHDB, this situation has been accounted as worse social performance, since corruption represents a breach of law.

The best ranked subcategories (as much better), were Public commitments to sustainability issues and Contribution to economic development, and Product social utility. The Contribution to economic development is measured by the multiplier effect 
calculated by an Input Output analysis performed previously by the authors (Corona, de la Rúa, and San Miguel 2016). The multiplier effect provides a measure of the increase in the national income as a result of the demand of goods or services by the project. Since the multiplier effect of the power plant was 2.60 , the indicator was ranked as much better.

Most of the subcategories affecting the local community were ranked as similar, since the power plant is located far from population centres, there is no high risk associated with this issues (according to the hotspots analysis) and it has been checked -through a visit to the facilities and local newspapers- that the corresponding social issues are not significantly affected.

According to these results, the social performance of the company should be improved by working in the gender and salary equality of workers, as well as fair competition and legality regarding influences and bank accounts.

Table 2 describes the work hours, weighting factors and weighted results for each impact category and life phase. The weighting factors were assigned in accordance with the corresponding labour intensity (measured in work hours), which gave higher weight to the O\&M phase. The total aggregated result of the CSP plant is $0.42 \mathrm{~s}-\mathrm{pp}$, which represents a slightly positive social impact in Spain ( $2 \mathrm{~s}-\mathrm{pp}$ would be the best score, while -2 s-pp points would be the worst). The category exhibiting the best social performance and positive social impacts within the country is Socio-economic sustainability, with $1.38 \mathrm{~s}-\mathrm{pp}$, followed by Fairness of relationships, with $0.29 \mathrm{~s}-\mathrm{pp}$. The category performing worst is Cultural and natural heritage, presenting a neutral performance (with 0 points). This neutral result is due to the similar ranking of every subcategory classified within this category, since they are not significantly affected by the power plant under study.

Table 4 Weighting step and social performance results according to impact categories for the whole life cycle of the power plant

\begin{tabular}{|l|l|l|l|l|}
\cline { 2 - 5 } \multicolumn{2}{|l|}{ WEIGHTING } & \multicolumn{2}{l|}{} \\
\cline { 2 - 4 } & C & O\&M & D & TOTAL \\
\hline
\end{tabular}




\begin{tabular}{|l|l|l|l|l|}
\hline Work hours per phase & 394357 & 1440256 & 82261 & 1916874 \\
\hline Weighting factors & 0.21 & 0.75 & 0.04 & 1 \\
\hline Labour Rights and Decent work & 0.04 & 0.12 & 0.00 & 0.17 \\
Cultural and natural heritage & 0.00 & 0.00 & 0.00 & 0.00 \\
Fairness of relationships & 0.06 & 0.21 & 0.01 & 0.29 \\
Socio-economic sustainability & 0.24 & 1.03 & 0.05 & 1.38 \\
\hline TOTAL & 0.08 & 0.31 & 0.02 & 0.42 \\
\hline
\end{tabular}




\section{Conclusions}

This paper presents a novel S-LCA methodological proposal based on a single social indicator aimed at evaluating the social performance of the life cycle of a product or service within a specific region. The presented methodology has been developed to maintain coherence with the structure of conventional E-LCA in the context of LCSA, but introduces some differences with respect to the E-LCA methodology. Qualitative information was evaluated in the analysis using a meaning assessment step that builds on a numeric equivalent scale and an activity variable that takes into consideration the number of worker hours associated with each activity and life cycle phase. The need to include social benefits/drawbacks in the S-LCA evaluation method was solved by including in the numeric scale negative/positive numbers representing deviation from social performance standards. The methodology tested in this case study was such that S-LCA impacts were primarily related to the social performance of the companies/countries involved in the life cycle of the system. In contrast, the technical characteristics of the system (such as power generation efficiency or power generation capacity) had a very limited influence on social performance.

Regarding the case study of the CSP plant, the generic assessment revealed that the life cycle phase contributing the highest to the social risk of the system is by far O\&M phase. This is mainly due to the consumption of natural gas, since $75 \%$ of the O\&M weighted risk is attributed to this process. The main social risks in Spain associated with the CSP plant are related to gender inequality, corruption, injuries and immigrants. The risk of gender inequality and corruption was confirmed by the sitespecific assessment, while social problems related to injuries and immigration were not detected.

The macro-level approach employed to evaluate generic social risks caused some misleading results, which had to be identified and evaluated on a case by case basis. For instance, the solar plant was allocated high weighted risks due to the economic interactions of the system with the metal and mineral sectors of Mozambique and Angola. However, a more precise investigation of material inputs employed in the 
construction of the power plant revealed a low probability of contribution from those countries to the value chain of the solar plant.

Results regarding the site-specific assessment suggest that provision of electricity from a CSP plant in Spain produces a slight but beneficial effect on the social welfare of the country. This increase is specially observed in the Socio-economic repercussions category. The impact category Cultural and Natural heritage remains unaltered by the power plant, while Labour Rights and Decent work category presents the lowest increase in social welfare. Results per subcategory indicate a negative social impact on Fair salary, Discrimination, Fair competence and Corruption. This situation could be improved by increasing gender equality and decreasing the wage gap between workers. Besides, the promoter company should make an effort to ensure full compliance with the legislation regarding fair competition, and to enforce internal procedures to guarantee transparency regarding the accounting and management of public funds.

This study is site-specific, using the Spanish social standard as a reference. Therefore, the results are only representative to the current context in Spain and may not be extrapolated elsewhere. An additional issue that needs consideration in this methodology refers to the limited scope of current S-LCA, since social impacts derive and evolve from the combination of a wide range of cultural and political issues, while existing S-LCA does not address such variability and complexity.

As for futures lines of research, it would be interesting to apply this methodology to other technologies in order to identify strengths and weaknesses as well as to compare results from different systems. It would be also enlightening to evaluate comparatively the effect of using alternative social impact methodologies/frameworks. Another research area of interest relates to the integration of the social assessment into the environmental and economic elements of sustainability in order to produce a comprehensive sustainability analysis of the technology.

\section{Acknowledgements}


This research was partially supported by the European Commission under the project Innovative Configuration for a Fully Renewable Hybrid CSP Plant FP7-ENERGY-2012-1 CP 308912.

References

Benoît Norris, C., M. Traverso, S. Valdivia, G. Vickery-Niederman, J. Franze, L. Azuero, A. Ciroth, B. Mazijn, and D. Aulision. 2013. The methodological sheets for sub-categories in social life cycle assessment (S-LCA). United Nations Environment Programme (UNEP) and Society for Environmental Toxicology and Chemiastry (SETAC).

Benoit-Norris, Catherine, Gregory A. Norris, and Deana Aulisio. 2013. The social hotspots database V2. New Earth, .

Brent, Alan C., and Carin Labuschagne. 2005. Sustainable life cycle management: A case study in the process industry to develop a calculation procedure for social indicators following conventional LCA methods. Paper presented at Fourth Australian conference on life cycle assessment, Sydney, .

Brundtland, Gro Harlem. 1987. Report of the world commission on environment and development:" Our common future."United Nations.

Burkhardt, John J.,III, Garvin Heath, and Craig Turchi. 2010. Life cycle assessment of a model parabolic trough concentrating solar power plant with thermal energy storage. ASME 2010 4th International Conference on Energy Sustainability. American Society of Mechanical Engineers: 599-608

Caldés, N., M. Varela, M. Santamaría, and R. Sáez. 2009. Economic impact of solar thermal electricity deployment in spain. Energy Policy 37 (5) (5): 1628-36.

Chhipi-Shrestha, Gyan Kumar, Kasun Hewage, and Rehan Sadiq. 2015. 'Socializing' sustainability: A critical review on current development status of social life cycle impact assessment method. Clean Technologies and Environmental Policy 17 (3) (MAR 2015): 579-96.

Cinelli, Marco, Stuart R. Coles, Andreas Jørgensen, Alessandra Zamagni, Chalaka Fernando, and Kerry Kirwan. 2013. Workshop on life cycle sustainability assessment: The state of the art and research needs-November 26, 2012, copenhagen, denmark. The International Journal of Life Cycle Assessment: 1-4.

Ciroth, Andreas, and Juliane Franze. 2011. LCA of an ecolabeled notebook: Consideration of social and environmental impacts along the entire life cycle. ISBN 978-1-4466-0087-0.

Corona, B., C. de la Rúa, and G. San Miguel. 2016. Socio-economic and environmental effects of concentrated solar power in spain: A multiregional input output analysis. Solar Energy Materials and Solar Cells. 
Corona, B., and G. San Miguel. 2015. Environmental analysis of a concentrated solar power (CSP) plant hybridised with different fossil and renewable fuels. Fuel 145 (0) (4/1): 63-9.

Dreyer, Louise, Michael Hauschild, and Jens Schierbeck. 2006. A framework for social life cycle impact assessment (10 pp). The International Journal of Life Cycle Assessment 11 (2): 88-97.

Ekener-Petersen, Elisabeth, and Goran Finnveden. 2013. Potential hotspots identified by social LCA-part 1: A case study of a laptop computer. International Journal of Life Cycle Assessment 18 (1) (JAN): 127-43.

INE. Mujeres y hombres en españa/ empleo. 2015 [cited 06/02 2015]. Available from http://www.ine.es/ss/Satellite?L=es_ES\&c=INESeccion_C\&cid=1259931459725\&p=1 254735110672\&pagename=ProductosYServicios\%2FPYSLayout\&param3=125992482 2888.

INE. 2014. Encuesta anual de estructura salarial año 2012.

Jørgensen, Andreas, Agathe Le Bocq, Liudmila Nazarkina, and Michael Hauschild. 2008. Methodologies for social life cycle assessment. The International Journal of Life Cycle Assessment 13 (2): 96-103.

Klein, Sharon JW, and Edward S. Rubin. 2013. Life cycle assessment of greenhouse gas emissions, water and land use for concentrated solar power plants with different energy backup systems. Energy Policy 63 : 935-50.

Kloepffer, Walter. 2008. Life cycle sustainability assessment of products. International Journal of Life Cycle Assessment 13 (2) (MAR 2008): 89-94.

Macombe, Catherine, Pekka Leskinen, Pauline Feschet, and Riina Antikainen. 2013. Social life cycle assessment of biodiesel production at three levels: A literature review and development needs. Journal of Cleaner Production 52 (0) (8/1): 205-16.

Martínez-Blanco, Julia, Annekatrin Lehmann, Pere Muñoz, Assumpció Antón, Marzia Traverso, Joan Rieradevall, and Matthias Finkbeiner. 2014. Application challenges for the social life cycle assessment of fertilizers within life cycle sustainability assessment. Journal of Cleaner Production 69 (0) (4/15): 34-48.

Ministry of foreign affairs. Fichas país. 2015 [cited 06/15 2015]. Available from http://www.exteriores.gob.es/portal/es/saladeprensa/paginas/fichaspais.aspx.

OECD. Prices and purchasing power parities. 2014 [cited 06/30 2014]. Available from http://stats.oecd.org/Index.aspx?DataSetCode=PPPGDP.

Parent, Julie, Carmela Cucuzzella, and Jean-Pierre Revéret. 2010. Impact assessment in SLCA: Sorting the sLCIA methods according to their outcomes. The International Journal of Life Cycle Assessment 15 (2): 164-71. 
Petti, Luigia, Ugaya, Cassia M. L. and Di Cesare, Silvia. Systematic review of sociallife cycle assessment (S-LCA) case studies. 20142014]. Available from http://acvsociale.cirad.fr/content/download/4260/31992/version/1/file/Thema+2+-+Sess14+Petti+et+al.+2014_4thSocSem_SLCA_Montpellier.pdf.

San Miguel, G., and B. Corona. 2014. Hybridizing concentrated solar power (CSP) with biogas and biomethane as an alternative to natural gas: Analysis of environmental performance using LCA. Renewable Energy 66 (0) (6): 580-7.

UNEP-SETAC Life Cycle Initiative. 2009. Guidelines for social life cycle assessment of products. United Nations Environment Programme.ISBN: 978-92. 